\title{
Pseudomonas aeruginosa strain MA01 aerobically metabolizes the aminodinitrotoluenes produced by 2,4,6-trinitrotoluene nitro group reduction
}

\author{
Marc A. Alvarez, Christopher L. Kitts, James L. Botsford, and \\ Pat J. Unkefer
}

\begin{abstract}
Many microbes reduce the nitro substituents of 2,4,6-trinitrotoluene (TNT), producing aminodinitrotoluenes (ADNTs). These compounds are recalcitrant to further breakdown and are acutely toxic. In a search for organisms capable of metabolizing ADNTs, a bacterial strain was isolated for the ability to use 2-aminobenzoate (anthranilate) as sole C-source. This isolate, Pseudomonas aeruginosa MA01, metabolized TNT by first reducing one nitro group to form either 2-amino-4,6-dinitrotoluene (2ADNT) or 4 -amino-2,6-dinitrotoluene (4ADNT). However, strain MA01 was distinct from other TNT-reducing organisms in that it transformed these compounds into highly polar metabolites through an $\mathrm{O}_{2}$-dependent process. Strain MA01 was able to cometabolize TNT, 2ADNT, and 4ADNT in the presence of a variety of carbon and energy sources. During aerobic cometabolism with succinate, $45 \%$ of uniformly ring-labeled $\left[{ }^{14} \mathrm{C}\right] \mathrm{TNT}$ was transformed to highly polar compounds. Aerobic cometabolism of purified $\left[{ }^{14} \mathrm{C}\right] 2 \mathrm{ADNT}$ and $\left[{ }^{14} \mathrm{C}\right] 4 \mathrm{ADNT}$ with succinate as $\mathrm{C}$-source produced similar amounts of these polar metabolites. During $\mathrm{O}_{2}$-limited cometabolism with succinate as $\mathrm{C}$-source and nitrate as electron acceptor, less than $8 \%$ of the $\left[{ }^{14} \mathrm{C}\right]$ TNT was transformed to polar metabolites. Purified 2,6-diamino-4-nitrotoluene was not metabolized, and while 2,4-diamino-6-nitrotoluene was acetylated, the product ( $N$-acetyl-2,4-diamino-6-nitrotoluene) was not further metabolized. Therefore, strain MA01 metabolized TNT by oxidation of the ADNTs and not by reduction the remaining nitro groups on the ADNTs.
\end{abstract}

Key words: 2,4,6-trinitrotoluene, aminodinitrotoluene, Pseudomonas aeruginosa, cometabolism.

\begin{abstract}
Résumé : Plusieurs microorganismes peuvent réduire les substituants nitrés du 2,4,6-trinitrotoluène (TNT) avec production d'aminodinitrotoluènes (ADNTs). Ces composés sont fortement toxiques et résistent à une dégradation plus poussée. Dans une recherche d'organismes qui seraient capables de métaboliser les ADNTs, nous avons isolé une bactérie capable d'utiliser le 2-aminobenzoate (anthranilate) comme source unique de carbone. Cet isolat, le Pseudomonas aeruginosa MA01, métabolisait le TNT par réduction au départ du groupe nitro à partir du 2-amino-4,6-dinitrotoluene (2ADNT) ou du 4-amino-2,6-dinitrotoluene (4ADNT). Cette souche MA01 était cependant différente des autres organismes capables de réduire le TNT par le fait qu'elle transformait ces composés en métabolites fortement polaires selon un processus dépendant de $\mathrm{O}_{2}$. Cette souche MA01 était capable de co-métaboliser le TNT, le 2ADNT et le 4ADNT en présence de diverses sources de carbone et d'énergie. Lors du co-métabolisme aérobie avec le succinate, on a mesuré que $45 \%$ du $\left[{ }^{14} \mathrm{C}\right] \mathrm{TNT}$ uniformément marqué sur l'anneau était transformé en composés hautement polaires. Le co-métabolisme en aérobiose du $\left[{ }^{14} \mathrm{C}\right] 2 \mathrm{ADNT}$ et du $\left[{ }^{14} \mathrm{C}\right] 4 \mathrm{ADNT}$ en présence du succinate comme seule source de $\mathrm{C}$ a produit des quantités comparables de métabolites polaires. Lors d'un co-métabolisme limité en $\mathrm{O}_{2}$ en présence de succinate comme source de $\mathrm{C}$ et de nitrate comme accepteur d'électrons, on a mesuré que moins de $8 \%$ du $\left[{ }^{14} \mathrm{C}\right] \mathrm{TNT}$ était transformé en métabolites polaires. Le 2,6-diamino-4-nitrotoluène purifié n'était pas métabolisé et même si le 2,4-diamino-6-nitrotoluène était acétylé, le produit obtenu
\end{abstract}

Received February 23, 1995. Revision received May 26, 1995. Accepted June 23, 1995.

M.A. Alvarez, C.L. Kitts, and P.J. Unkefer. ${ }^{1}$ Chemical Science and Technology Division, CST-18, Los Alamos National Laboratory, Los Alamos, NM 87545, U.S.A.

J.L. Botsford. Department of Biology, New Mexico State University, Las Cruces, NM 88003, U.S.A.

1 Author to whom all correspondence should be addressed. 
( $N$-acétyl-2,4-diamino-6-nitrotoluène) ne pouvait pas être métabolisé. En conclusion, la souche MA01 métabolise le TNT par oxydation des ADNTs mais pas par réduction des groupements nitrés encore présents sur les ADNTs.

Mots clés : 2,4,6-dinitrotoluène, aminodinitrotoluène, Pseudomonas aeruginosa, co-métabolisme.

[Traduit par la rédaction]

\section{Introduction}

Nitroaromatic compounds are used extensively in the explosives industry as well as for pesticides, dyes, and various other consumer products (Hartter 1985). The extensive use of 2,4,6-trinitrotoluene (TNT) at numerous military installations worldwide has resulted in the contamination of soils and groundwater. This compound is toxic, causing red blood cell abnormalities, liver dysfunction, and cancer in mammals (Hartter 1985; Hathaway 1985; Kaplan and Kaplan 1982).

Microbial degradation of TNT requires the removal of the aromatic-nitro substituents by any of three methods. One possible mechanism is the oxidative removal of aromatic-nitro substituents by a mono- or di-oxygenase enzyme producing nitrite and a hydroxylated aromatic nucleus. This mechanism is observed in microorganisms that degrade mono- and dinitrosubstituted toluenes (Robertson et al. 1992; Spain et al. 1979; Spanggord et al. 1991; Valli et al. 1992; Zeyer and Kocher 1988). However, this mechanism has not been reported for metabolism of trinitro substituted aromatic compounds. A second mechanism removes nitro groups from trinitro aromatic compounds by a reductive mechanism that proceeds through a "meisenheimer complex" intermediate, followed by the loss of nitrite from the aromatic nucleus (Duque et al. 1993; Vorbeck et al. 1994). A third mechanism for removing the nitrogenous substituents could begin with reduction to the aromatic amine, followed by removal of the amino group in a manner similar to the action of documented aniline degrading bacteria (Loidl et al. 1990).

Microbial transformation of TNT usually begins with the reduction of the nitro groups to produce 2-amino-4,6dinitrotoluene (2ADNT), 4-amino-2,6-dinitrotoluene (4ADNT), diaminonitrotoluene isomers (DANTs), and occasionally triaminotoluene (TAT). Polymeric azoxy compounds, tetranitroazoxytoluene isomers (TNATs), can also be formed by the abiotic condensation of partially reduced nitro groups on two TNT molecules. The ability to reduce the nitro groups on nitroaromatic compounds is quite broadly distributed among microorganisms, including Pseudomonas, Bacillus, Salmonella, Streptomyces, Phanerochaete, and several enteric bacterial genera (Boopathy et al. 1994; Bryant and DeLuca 1991; Cartwright and Cain 1959; Einistö et al. 1991; Fernando et al. 1990; Glaus et al. 1992; Kitts et al. 1994; Klausmeier et al. 1976; Naumova et al. 1986; Schackmann and Müller 1991). Therefore, attempts to degrade TNT using natural heterogeneous cultures often results in the production and significant accumulation of aminonitrotoluenes (Carpenter et al. 1978; Funk et al. 1993; Hallas and Alexander 1983; Williams et al. 1988). These aminonitrotoluenes are not readily biodegradable in natural heterogeneous cultures. Few studies have focused on metabolism of the aminonitrotoluenes. One such study identified TAT as a product of anaerobic microbial reduction of TNT and also detected methylphloroglucinol, phloroglucinol, and pyrogallol in the culture medium (Funk et al. 1993). However, no reports have specifically examined the aerobic metabolism of aminonitrotoluenes.

In this work, an organism isolated from sewer sludge was able to aerobically metabolize TNT and its reduction products. This organism, Pseudomonas aeruginosa MA01, grew on anthranilate(2-aminobenzoate) as a sole C-source and could thus deaminate and cleave the aromatic ring of anthranilate. Aerobic metabolism of TNT by this strain was initiated by the reduction of one nitro substituent to form aminodinitrotoluene (ADNT) isomers. The next step was an $\mathrm{O}_{2}$-dependent transformation of the ADNTs to form several highly polar compounds.

\section{Materials and methods}

\section{Isolation and characterization of organisms}

A bacterial strain with the capacity to utilize anthranilate as the sole carbon and energy source was isolated from sludge collected at a solid waste treatment facility (Alvarez 1993). The bacterial isolate was identified by means of the Gram-negative Biolog ${ }^{\circledR}$ identification system (Bochner and Savageau 1977) and additional biochemical tests selected from Bergey's Manual of Systematic Bacteriology (Palleroni 1984).

\section{Culture preparation and measurement of growth}

Strain MA01 was grown in minimal salts medium (Alvarez 1993) supplemented with $0.44 \mathrm{mM} \mathrm{TNT}$ with $15 \mathrm{mM}$ succinate as the primary source of carbon and energy. Cultures were grown in 1-L fluted culture flasks and incubated at $30^{\circ} \mathrm{C}$ in a rotary shaker $(150 \mathrm{rpm})$. During extended growth periods the cultures were fed an additional $15 \mathrm{mM}$ succinate every $12 \mathrm{~h}$. Turbidity of the cultures was monitored at $560 \mathrm{~nm}$ using a Hitachi model U-1100 UV/VIS spectrophotometer.

$\mathrm{O}_{2}$-limited cultures of $P$. aeruginosa MA01 were grown in 1-L fluted culture flasks with $200 \mathrm{~mL}$ of minimal salts medium supplemented with $0.44 \mathrm{mM} \mathrm{TNT}, 100 \mu \mathrm{Ci}(1 \mathrm{Ci}=37 \mathrm{GBq})$ uniformly ring-labeled $\left[{ }^{14} \mathrm{C}\right] \mathrm{TNT}, 30 \mathrm{mM}$ nitrate, and $15 \mathrm{mM}$ succinate. The medium was inoculated with exponentially growing cultures to an OD of 0.25 , stoppered, and incubated at $30^{\circ} \mathrm{C}$ at $150 \mathrm{rpm}$ in a rotary shaker for $170 \mathrm{~h}$. Control cultures were grown in unstoppered flasks in the same conditions. At 24-h intervals the cultures were supplemented with $15 \mathrm{mM}$ succinate and $10 \mathrm{mM}$ nitrate. At the end of the growth period, cultures were centrifuged at $14000 \times g$ for $15 \mathrm{~min}$, the supernatant fraction was decanted, and HPLC fractions were collected and counted as described below.

\section{Analytical methods}

Nitrite concentrations were monitored during growth using a standard assay (Gerhardt 1981). Both anthranilate dioxygenase and catechol dioxygenase were assayed as described previously (Gerhardt 1981). One-millilitre samples for HPLC analysis were taken from growing cultures and centrifuged at $14000 \mathrm{rpm}$ for $5 \mathrm{~min} ; 375 \mu \mathrm{L}$ of the culture medium and 
$375 \mu \mathrm{L}$ acetonitrile were combined and filtered $(0.2 \mu \mathrm{m})$. The filtrate was then analyzed using a Hewlett Packard model 1090 HPLC. Chromatography was accomplished with a $150 \times 4.6 \mathrm{~mm} \mathrm{C8}$ reverse-phase column with a HPLC grade $\mathrm{H}_{2} \mathrm{O}\left(\mathrm{pH} 2.6, \mathrm{H}_{2} \mathrm{SO}_{4}\right)$ - acetonitrile solvent system. The mobile phase was pumped at $1.0 \mathrm{~mL} / \mathrm{min}$ with a composition of $10 \%$ acetonitrile for $4 \mathrm{~min}$ and ramped to $50 \%$ over $9 \mathrm{~min}$. After 15-min total run time the mobile phase composition was ramped to $85 \%$ acetonitrile over a $1-\mathrm{min}$ period and held at $85 \%$ for the rest of the run. Photometric detection of TNT disappearance and intermediate accumulation was monitored at $230 \mathrm{~nm}$ and UV absorbance spectra of eluted compounds were recorded with an in-line diode array detector (Hewlett Packard). TNT and the products of TNT nitro group reduction (ADNTs and DANTs) have equivalent extinction coefficients at $230 \mathrm{~nm}$ (Vanderberg et al. 1995) that allow for estimation of their relative concentrations from HPLC peak areas.

\section{Isolation and experimentation using ADNTs}

The isolation of 2ADNT and 4ADNT was accomplished by growing Citrobacter freundii NS2 (Kitts et al. 1994) in a minimal salts medium (Alvarez 1993) supplemented with $0.5 \%$ yeast extract and $11 \mathrm{mM}$ glucose. A culture volume of $1.8 \mathrm{~L}$ was placed in a 2-L fluted culture flask then fitted with a silicone stopper to ensure low aeration. The cultures were grown for $48 \mathrm{~h}$ or $140 \mathrm{~h}$, at $30^{\circ} \mathrm{C}$ in a rotary shaker $(150 \mathrm{rpm})$ to produce ADNTs and DANTs, respectively. Cultures were centrifuged at $14000 \times g$ for $15 \mathrm{~min}$. The supernatant fraction was decanted and twice extracted in a separatory funnel using equal volumes of anhydrous diethylether. The organic phase was reduced to dryness using a Buchi model 111 rotary evaporator. The concentrate was resuspended in acetonitrile and filtered on Waters C18 Seppak ${ }^{\circledR}$ cartridges and injected onto a Rainin HPLC system equipped with a C8 Rainin Microsorb $21.4 \times 25 \mathrm{~cm}$ semipreparative column. Separation of DANT isomers and N(4)-acetyl-2,4-amino-6-nitrotoluene (ADANT) was performed using a 23\% acetonitrile and $77 \%$ acidified $\mathrm{H}_{2} \mathrm{O}$ isocratic protocol at a flow rate of $20 \mathrm{~mL} / \mathrm{min}$. The identity and purity of the isolated compounds were confirmed using an HP1090 HPLC system interfaced to an HP5989A mass spectrometer, utilizing negative ion thermospray. In addition, proton nuclear magnetic resonance spectra ( $\left.{ }^{1} \mathrm{H}-\mathrm{NMR}\right)$ were obtained with some compounds using a Bruker AMX-500 spectrometer. Cultures using purified ADNTs and DANTs were set up in the same manner as the aforementioned TNT experiments.

\section{Mass balance determination}

Minimal salts medium was prepared with $0.44 \mathrm{mM}$ TNT and supplemented with $\left[{ }^{14} \mathrm{C}\right] \mathrm{TNT}(21.6 \mathrm{Ci} / \mathrm{mol}, 98 \%$ radiochemical purity, Chemsyn Science Labs, Lenexa, Kans.) to yield a total activity of $8.3 \times 10^{7} \mathrm{cpm}$ in $200 \mathrm{~mL}$. Cultures were set up in 1-L fluted culture flasks fitted with silicone stoppers and tygon tubing to allow for flushing of the system. The effluent gas stream was flushed through a volatile organic trap (Supelco) and then through $200 \mathrm{~mL}$ of $5 \mathrm{M} \mathrm{NaOH}$ to trap evolved ${ }^{14} \mathrm{C}$ volatile organics and $\left[{ }^{14} \mathrm{C}\right] \mathrm{CO}_{2}$. After $170 \mathrm{~h}$ of growth, cells were fractionated according to Alvarez (1993). The radioactive content of each fraction was determined by scintillation counting using Ultima Gold scintillation cocktail in a Packard Minaxi Tri Carb 4000 series liquid scintillation system. Further fractionation of the radiolabeled components remaining in solution was performed by HPLC as described above, collecting 0.5 -min fractions of the column eluent with a Gilson model 201 fraction collector.

Isolation of $\left[{ }^{14} \mathrm{C}\right] \mathrm{ADNT}$ s was accomplished by growing C. freundii NS2 (Kitts et al. 1994) on a minimal salts medium supplemented with $0.5 \%$ yeast extract, $11 \mathrm{mM}$ glucose, $0.88 \mathrm{mM}$ TNT, and $100 \mu \mathrm{Ci}$ of $\left[{ }^{14} \mathrm{C}\right] \mathrm{TNT}$ under the same culture conditions described above for production of unlabeled ADNTs. Purification of the 2ADNT and 4ADNT was accomplished as described with unlabeled ADNTs. Mass balance, fractionation, and scintillation counting was performed in the same manner as with experiments using $\left[{ }^{14} \mathrm{C}\right] \mathrm{TNT}$.

\section{Extraction of polar intermediates at different pHs}

Ether extraction at various pHs were accomplished by taking 15 -mL aliquots of the supernatant fraction from the end points of TNT, 2ADNT, and 4ADNT metabolism experiments. The $15-\mathrm{mL}$ aliquots were titrated to $\mathrm{pH}$ values of $2.0,7.0$, and 12.0 . The titrated solutions were divided into $5-\mathrm{mL}$ fractions, and each fraction was extracted twice with equal volumes of anhydrous diethyl ether. The organic phase was decanted, the aqueous fractions were neutralized, and scintillation counting was performed as described above. The organic phases were dried, resuspended in a $3: 2$ acetonitrile $-\mathrm{H}_{2} \mathrm{O}$ solution, and further fractionated using the HPLC method described above.

\section{Results}

\section{Isolation and identification of an organism that metabolizes} anthranilate, and amino-aromatic compound

A single Gram-negative organism, capable of using anthranilate as sole $\mathrm{C}$-source, was isolated from the solid waste processing area at a municipal waste treatment plant. The isolate was identified as $P$. aeruginos $a$ using the Biolog ${ }^{\circledR}$ Gramnegative identification system (97\% confidence level) (Alvarez 1993; Bochner and Savageau 1977) and by a series of biochemical tests selected from Bergey's Manual of Systematic Bacteriology (Palleroni 1984). The isolate, named strain MA01, produced phenazine and pyochelin pigments, catabolized anthranilate through the oxidative formation of catechol, and opened the aromatic ring by the orthocleavage mechanism (Gerhardt 1981).

\section{Pseudomonas aeruginosa MA01 cometabolized TNT with a variety of $\mathrm{C}$-sources}

Strain MA01 could not grow on TNT as either sole C-source or sole $\mathrm{N}$-source. However, when cultured in media containing TNT and another source of carbon and energy, strain MA01 was able to cometabolize TNT (Table 1). Of the C-sources tested, succinate, $\beta$-hydroxybutyrate, and anthranilate supported the least amounts of the aminonitrotoluenes accumulating in the medium. Although anthranilate was also a suitable C-source for TNT metabolism, recognition and subsequent identification of TNT metabolites were complicated by the accumulation of several anthranilate metabolites. Since growth on $\beta$-hydroxybutyrate was slow compared with succinate, we continued our study of TNT cometabolism by strain MA01 using succinate as $\mathrm{C}$-source and ammonium as $\mathrm{N}$-source. 
Fig. 1. Metabolism of TNT by strain MA01 during aerobic growth on succinate. Points plotted are averages of duplicate cultures and standard error did not exceed $10 \% .0$, area of peaks eluting between 6 and $11 \mathrm{~min}$ (ADANT, DANTs); $\square$, area of peak eluting at $13.6 \mathrm{~min}$ (2ADNT); $\boldsymbol{\square}$, area of peak eluting at $13.8 \mathrm{~min}$ (4ADNT); $\times$, area of peak eluting at $16.8 \mathrm{~min}$ (TNT); $\Delta$, area of peaks eluting between 20.2 and $21.0 \mathrm{~min}$ (TNATs); - - -, culture density (absorbance at $560 \mathrm{~nm}$ ).

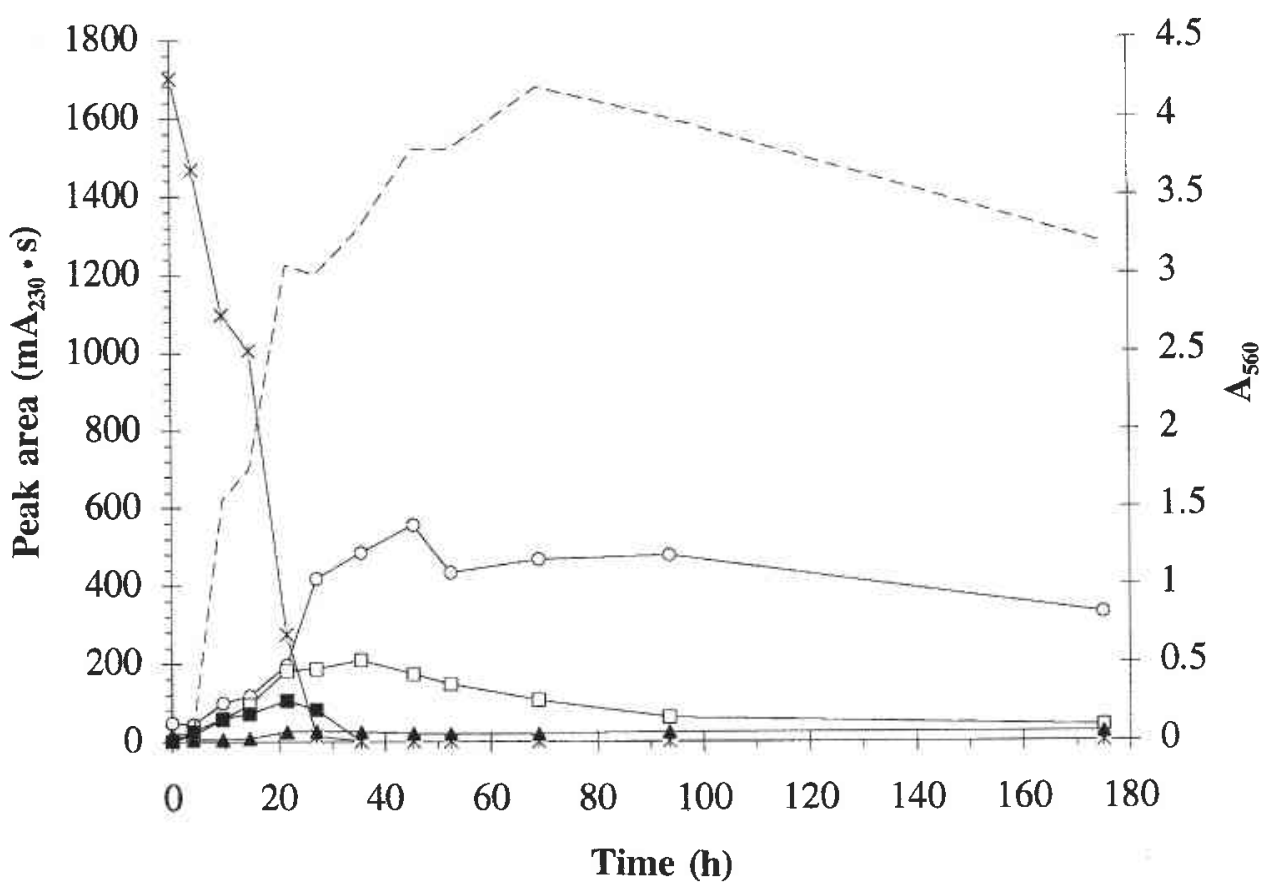

\section{TNT metabolism by Pseudomonas aeruginosa MA01 was initiated by reduction of the nitro groups}

Strain MA01, grown with $0.44 \mathrm{mMTNT}$ and $15 \mathrm{mM}$ succinate, produced several compounds identified as products of TNT nitro group reduction (Table 2). Transient accumulation of ADNT isomers in the culture medium was followed by the appearance of DANTs, TNATs, and ADANT, a compound not usually observed during TNT metabolism (Fig. 1). Soluble nitrite concentration was monitored throughout the experiment and remained below $3 \mu \mathrm{M}$ (detection limit). After 1 week of incubation, the total peak area from all identified TNT reduction products could not account for the initial TNT peak area. Therefore, some TNT reduction products must have been further metabolized by strain MA01.

\section{Pseudomonas aeruginosa MA01 metabolizes ADNTs but not DANTs}

Strain MA01 was incubated with either purified 2ADNT $(0.07 \mathrm{mM})$ or purified 4ADNT $(0.11 \mathrm{mM})$ to further examine its ability to metabolize these compounds. During a 1-week incubation period, $2 \mathrm{ADNT}$ was $88 \%$ metabolized and 2,4diamino-6-nitroluene (2,4-DANT), 2,6-diamino-4-nitrotoluene (2,6-DANT), and ADANT were detected in the culture medium. Over the same period of time 4ADNT was $94 \%$ metabolized, with 2,4-DANT and ADANT detected in the culture medium. As with TNT, the total peak area due to identified intermediates present after 1 week of incubation could not account for the initial peak area from either ADNT isomer.
Table 1. Effects of different carbon substrates on TNT metabolism by $P$. aeruginosa MA01.

\begin{tabular}{lccc}
\hline Carbon substrate* & $\begin{array}{c}\text { TNT removal } \\
\text { time (h) }\end{array}$ & $\begin{array}{c}\text { Reduction } \\
\text { products }^{\dagger}\end{array}$ & $\begin{array}{c}\text { Generation } \\
\text { time (h) }\end{array}$ \\
\hline Succinate & 48 & 20 & 1.89 \\
$\beta$-Hydroxybutyrate & 33 & 20 & 3.26 \\
Anthranilate & 45 & $25^{\ddagger}$ & 1.89 \\
Lactate & 24 & 30 & 1.10 \\
Glucose & 16 & 34 & 2.42 \\
$\alpha$-Ketoglutarate & 24 & 36 & 1.32 \\
Adipate & 36 & 50 & 1.89 \\
\hline
\end{tabular}

*Cultures grown in minimal salts medium for $170 \mathrm{~h}$ with $0.1 \mathrm{mg} \mathrm{TNT} / \mathrm{mL}$ and supplemented at 12 -h intervals with the respective carbon source.

TNT nitro group reduction products (ADNTs, DANTs, ADANT, and TNATs). Concentrations of intermediates are presented as a percentage of the initial concentration of TNT (see Materials and methods) and expressed as an average of duplicate cultures.

¥Approximate reduction product accumulation because of interference by anthranilate degradation products.

The metabolic fates of the DANTs were not the same as those of the ADANTs. Ninety percent of the 2,4-DANT was acetylated and the product ADANT was not further metabolized. 2,6-DANT was not metabolized or transformed during 1 week of incubation with strain MA01. These findings imply that metabolism of TNT did not continue past the formation of the DANTs. 
Table 2. Identification of TNT metabolites.

\begin{tabular}{llccc}
\hline Compound & Abbr. & $\begin{array}{c}\text { HPLC } \\
\text { retention time* }\end{array}$ & $\begin{array}{c}\text { Mol. wt. } \\
\text { (LC-MS) }{ }^{\dagger}\end{array}$ & $\begin{array}{c}{ }^{1} \mathrm{H}-\mathrm{NMR} \text { peaks, } \\
\text { chemical shift (ppm) } \neq\end{array}$ \\
\hline 2,4,6-Trinitrotoluene & TNT & $16.8^{\S}$ & 227 & nd \\
2-Amino-4,6-dinitrotoluene & 2ADNT & 13.6 & 197 & $2.15,6.27,7.69,7.73$ \\
4-Amino-2,6-dinitrotoluene & 4ADNT & 13.8 & 197 & $2.20,6.18,7.28$ \\
2,4-Diamino-6-nitrotoluene & 2,4-DANT & 8.2 & 167 & nd \\
2,6-Diamino-4-nitrotoluene & 2,6-DANT & $6.8 \S$ & 167 & nd \\
$N$ (4)-Acetyl-2,4-diamino-6-nitrotoluene & ADANT & 10.5 & 209 & $1.98,1.97,5.23,7.07,7.24,9.93$ \\
Tetranitroazoxytoluene isomers & TNATs & $20.2-21.0$ & 406 & nd \\
\hline
\end{tabular}

*Retention time in minutes using the analytical HPLC protocol (see Materials and methods).

Molecular weight determined as the parent ion using liquid chromatography mass spectrometry equipped with a thermospray probe, run in negative ion detection mode. This method gave parent ions only; no fragmentation ions were apparent.

FApproximate chemical shift assignments: aromatic- $\mathrm{CH}_{3}, 2 \mathrm{ppm}$; aromatic-NH $\mathrm{NH}_{2}, 5-6 \mathrm{ppm}$; aromatic-H, 7-8 ppm; amide-H, $10 \mathrm{ppm}$. nd, not determined.

\&etention times identical to standard compounds.

Table 3. Relative distribution of radiolabel in cultures of $P$. aeruginosa MA01.

\begin{tabular}{llrrr}
\hline & & \multicolumn{2}{c}{ Labeled compound supplied } \\
\cline { 3 - 4 } Fraction & Fraction obtained & TNT* & 2ADNT & 4ADNT ${ }^{\dagger}$ \\
\hline Culture medium & Supernatant & 81.2 & 78.5 & 75.7 \\
NaCl wash & Supernatant & 4.6 & 7.1 & 5.0 \\
Cold TCA & Carbohydrate & 0.1 & 0.4 & 0.3 \\
Alcohol, ether soluble & Lipid & 4.2 & 0.4 & 0.3 \\
Alcohol soluble, ether insoluble & Protein & 0.2 & 0.2 & 0.2 \\
Hot TCA & Nucleic acid & 0.2 & 0.5 & 0.4 \\
Pellet wash & & 0.4 & 0.2 & 0.2 \\
HCl hydrolysis & Protein & 0.4 & 0.5 & 1.2 \\
Cell debris & Residue & 2.1 & 0.3 & 1.3 \\
NaOH trap & $14 \mathrm{CO}_{2}$ & 0.7 & 1.0 & 1.0 \\
Antifoam wash & & 3.4 & 5.9 & 9.6 \\
Volatile organic trap & & $<0.1$ & $<0.1$ & $<0.1$ \\
\% Radiolabel recovered & & 97.5 & 95.0 & 95.2 \\
\hline
\end{tabular}

*Distribution as a percentage of initial $\left[{ }^{14} \mathrm{C}\right]$ TNT $\left(8.3 \times 10^{7} \mathrm{cpm}\right.$ total $)$ after $170 \mathrm{~h}$ of incubation.

Distribution as a percentage of initial $\left[{ }^{14} \mathrm{C}\right] 2 \mathrm{ADNT}\left(4.8 \times 10^{6} \mathrm{cpm}\right.$ total $)$ after $170 \mathrm{~h}$ of incubation.

Distribution as a percentage of initial $\left[{ }^{14} \mathrm{C}\right] 4 \mathrm{ADNT}\left(1.1 \times 10^{7} \mathrm{cpm}\right.$ total $)$ after $170 \mathrm{~h}$ of incubation.

Table 4. Percentage of radiolabel in intermediates from culture medium of $P$. aeruginosa MA01 after $170 \mathrm{~h}$ incubation with TNT, 2ADNT, and 4ADNT.

\begin{tabular}{|c|c|c|c|c|c|}
\hline \multirow[b]{2}{*}{ Intermediate(s) } & \multirow[b]{2}{*}{$\begin{array}{l}\text { HPLC } \\
\text { retention time (min) }\end{array}$} & \multicolumn{4}{|c|}{ Radiolabel supplied } \\
\hline & & $\mathrm{TNT}^{*}$ & $\begin{array}{c}\mathrm{TNT}^{\dagger} \\
\left(\mathrm{O}_{2} \text { limited }\right)\end{array}$ & $2 \mathrm{ADNT}^{\ddagger}$ & $4 \mathrm{ADNT}^{\S}$ \\
\hline Polar compounds & $2-4$ & 57.0 & 9.6 & 53.4 & 58.6 \\
\hline DANTs & $6-9$ & 16.6 & 17.1 & 24.5 & 21.5 \\
\hline ADANT & 10.5 & 6.2 & 7.6 & 3.3 & 12.1 \\
\hline ADNTs & $13-14$ & 5.2 & 59.6 & 11.9 & 4.5 \\
\hline TNATs & $20-21$ & 5.7 & 2.0 & 2.9 & 0.2 \\
\hline
\end{tabular}

*Percentage of label in the culture medium $\left(6.7 \times 10^{7} \mathrm{cpm}\right.$ total $)$ after $170 \mathrm{~h}$ of incubation.

Percentage of label in the culture medium $\left(1.2 \times 10^{8} \mathrm{cpm}\right.$ total $)$ after $170 \mathrm{~h}$ of incubation.

Percentage of label in the culture medium $\left(3.8 \times 10^{6} \mathrm{cpm}\right.$ total $)$ after $170 \mathrm{~h}$ of incubation.

${ }^{\S}$ Percentage of label in the culture medium $\left(8.3 \times 10^{6} \mathrm{cpm}\right.$ total $)$ after $170 \mathrm{~h}$ of incubation. 


\section{Highly polar compounds were formed during TNT, 2ADNT, and 4ADNT metabolism}

Because the TNT reduction products identified above did not appear to account for all of the TNT initially present, we followed the metabolic fate of TNT using radiolabeled compounds. After 1 week of incubating strain MA01 with uniformly ring-labeled $\left[{ }^{14} \mathrm{C}\right] \mathrm{TNT}(0.5 \mu \mathrm{Ci} / \mathrm{mL})$, all components of the incubation were fractionated (see Materials and methods) and a mass balance was obtained by scintillation counting of the fractions (Table 3). Approximately $81 \%$ of the initial radiolabel was associated with the culture medium. Fractionation of the culture medium using HPLC indicated that about $57 \%$ of the radiolabel in the medium (45\% of the total radiolabel) was associated with highly polar compounds eluting within the first 4 min (Table 4; Fig. 2). UV-absorbing metal chelators (Palleroni 1984) excreted into the medium coeluted with the radiolabled polar compounds, complicating structural analysis of the metabolites (Fig. 2). About $4 \%$ of the total radioactivity was present in the lipid fraction. Analysis of the lipid fraction by HPLC showed that the radioactivity was present in TNAT isomers. Very little radioactivity was associated with the $\mathrm{CO}_{2}$, volatile organic, protein, and nucleic acid fractions.

To confirm that TNT and the ADNTs were metabolized to a similar extent, experiments were conducted using purified, uniformly ring-labeled $\left[{ }^{14} \mathrm{C}\right] 2 \mathrm{ADNT}$ and $\left[{ }^{14} \mathrm{C}\right] 4 \mathrm{ADNT}$. At the end of both experiments the distribution of radiolabel closely matched that seen when $\left[{ }^{14} \mathrm{C}\right] \mathrm{TNT}$ was used (Table 3). In each case the majority of the radiolabel was in the culture medium fraction and predominantly found as polar compounds of a similar chromatographic nature to those produced during TNT metabolism (Table 4). With respect to the 2ADNT and 4ADNT experiments, 53 and $59 \%$ of the radiolabel remaining in the culture medium ( 40 and $44 \%$ of the total radiolabel) was associated with these polar metabolites. These values are quite similar to results with TNT. Once again, accumulation of chelating pigments obscured any UV-absorbing character these polar metabolites may have had.

To probe the nature of these metabolites we extracted the culture medium from all three ${ }^{14} \mathrm{C}$-labeling experiments (TNT, 2ADNT, 4ADNT) with diethyl ether. HPLC analysis revealed the residual ADNTs and DANTs were extracted into the organic phase, while the polar metabolites remained in the aqueous phase in all three cases. Moreover, these polar metabolites remained in the aqueous phase when extracted under either acidic $(\mathrm{pH} 2)$ or alkaline ( $\mathrm{pH} 12)$ conditions.

\section{Polar metabolite production was greatly reduced under $\mathrm{O}_{2}$-limited conditions}

During aerobic incubations of strain MA01 with either radiolabeled TNT, 2ADNT, or 4ADNT, $40-45 \%$ of the total radioactivity was associated with the polar metabolites. However, during 1 week of $\mathrm{O}_{2}$-limited incubation with nitrate $(30 \mathrm{mM})$ as the electron acceptor, less than $10 \%$ of the radiolabel remaining in solution $(<8 \%$ of the total radiolabel) was associated with the polar metabolites that elute in the first $4 \mathrm{~min}$ (Table 4). The formation of a small amount of polar metabolites in the $\mathrm{O}_{2}$-limited culture could be due to the introduction of dissolved $\mathrm{O}_{2}$ when the culture was fed. ADNTs accumulated in the $\mathrm{O}_{2}$-limited culture and accounted for $50 \%$ of the total radiolabel. Oxygen availability did not affect the percentage of
Fig. 2. Separation of TNT metabolites after $170 \mathrm{~h}$ of aerobic incubation. The upper panel contains the HPLC chromatogram. The lower panel shows the distribution of radioactivity as a percent of the total radiolabel injected on the HPLC column and collected in 0.5 -min fractions. The inserts in the upper and lower panels depict the initial chromatogram and initial distribution of radioactivity, respectively. Identified peaks on the HPLC chromatogram are indicated with the appropriate abbreviation (see Table 2).

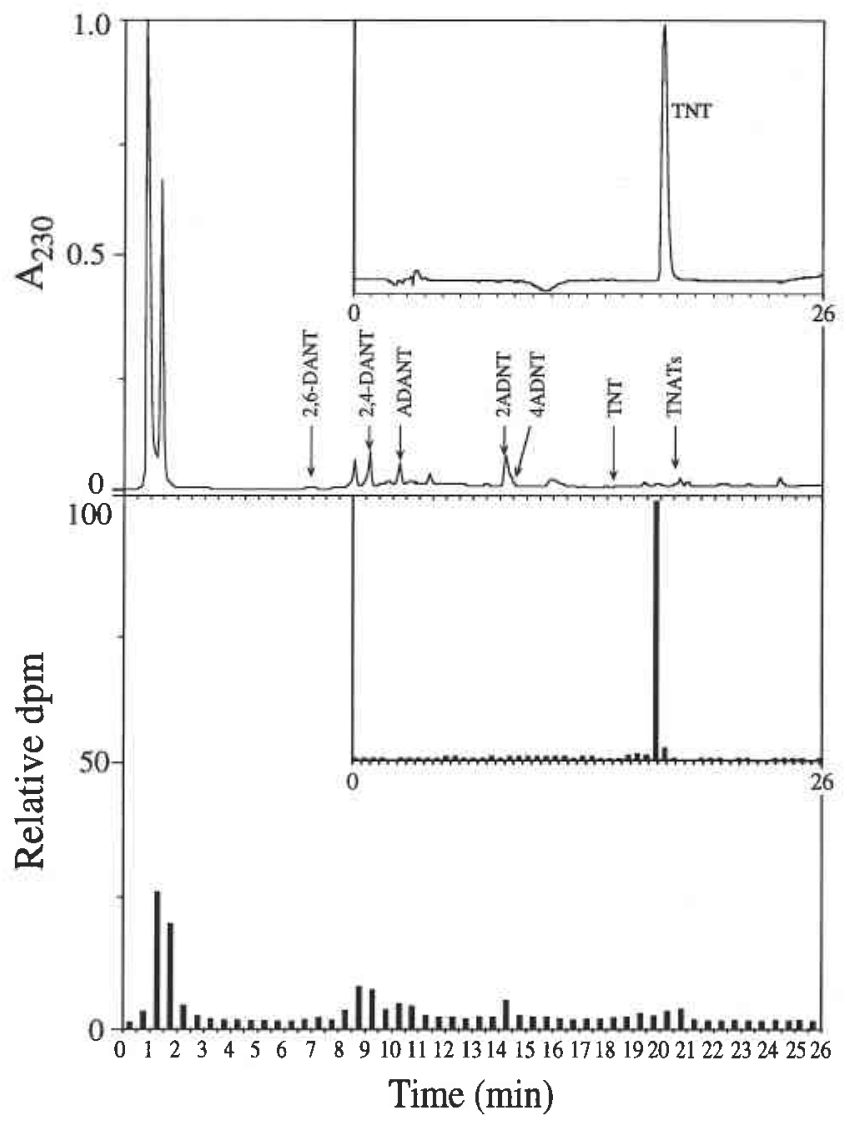

radiolabel associated with the DANTs. Addition of nitrate to aerated cultures did not effect the aerobic metabolism of the ADNTs formed from TNT. Thus, efficient metabolism of the ADNTs and formation of the polar metabolites appeared to require $\mathrm{O}_{2}$.

\section{Discussion}

We isolated an organism exhibiting amino-aromatic deaminase and aromatic ring cleavage activities that was able to cometabolize TNT in an aerobic process with succinate as carbon and energy source. As is the case with a variety of microorganisms, the metabolism of TNT by $P$. aeruginosa MA01 was initiated by reduction of one nitro substituent to form 2ADNT and 4ADNT (Fig. 1). However, unlike other organisms that reduce the nitro groups of TNT, strain MA01 did not accumulate large amounts of these reduction products and was able to metabolize them further. In the majority of biological systems studies, the nitro substituents of TNT are reduced, resulting in production of TNATs, ADNTs, DANTs, and in some cases TAT (Funk et al. 1993; Hallas and Alexander 1983; Klausmeier et al. 1976; McCormick et al. 1976; 
Schackmann and Müller 1991). Although P. aeruginosa MA01 produced DANTs and TNATs (Table 1), total accumulation of these dead-end reduction products was minimal (Table 1; Fig. 1). In fact, the metabolism of TNT followed an unusual pathway whereby the ADNT isomers were aerobically metabolized to form several unidentified polar compounds.

Succinate was the best carbon and energy source for TNT metabolism because of a combination of rapid growth, minimal accumulation of aminonitrotoluenes, and extent of further metabolism of the aminonitrotoluenes (Table 1; Fig. 1). The C-sources that supported the most rapid transformation of TNT (glucose and $\alpha$-ketoglutarate) also resulted in the largest accumulations of dead-end reduction products. Thus, rapid reduction of TNT appears to proceed at a faster rate than does the further aerobic metabolism of the ADNTs, and the dead-end reduction products (ADANT, DNATs and TNATs) accumulate.

When $\left[{ }^{14} \mathrm{C}\right]$ TNT was cometabolized by strain MA01, the majority of the radiolabel remaining in the culture medium was associated with highly polar compounds (Tables 3 and 4). Results were similar using either ${ }^{14} \mathrm{C}$-labeled ADNT isomer in place of $\left[{ }^{14} \mathrm{C}\right] \mathrm{TNT}$ (Tables 3 and 4). These compounds could not be extracted into diethyl ether from either an acidic or a basic aqueous solution, suggesting an amphoteric structure. Amphoteric compounds that could have been generated include an aminobenzoic acid or a ring breakage product.

Aerobically grown cultures of strain MA01 produced much greater amounts of the polar compounds and accumulated much smaller amounts of the ADNTs when compared with $\mathrm{O}_{2}$-limited cultures (Table 4). Consequently, the formation of these polar metabolites must be an $\mathrm{O}_{2}$-dependent process and may reflect the action of a mono- or di-oxygenase enzyme system on the ADNT isomers. Clearly, this Pseudomonas strain contains at least two dioxygenase enzymes, the anthranilate dioxygenase and the catechol dioxygenase.

Because nitrite was not detected during TNT metabolism, oxidative removal of TNT nitro groups can be eliminated. Thus, oxidative metabolism of the ADNTs could occur following two different pathways. First, the initial oxidation of ADNTs may occur at the methyl group, with subsequent production of aminodinitrobenzoate isomers. Oxidation of TNT in this manner was detected in Mycobacterium vaccae (Vanderberg et al. 1995). Aminodinitrobenzoate oxidation by a decarboxylase, similar in action to anthranilate dioxygenase, could then produce aminonitrocatechol isomers, primed for ring breakage by a catechol dioxygenase. Second, the ADNT isomers could be acted upon by an oxidative deaminase similar in action to an aniline oxygenase (Loidl et al. 1990). Once again, ring breakage could occur by the action of a catechol dioxygenase on the resulting dinitromethylcatechol isomers. Investigations focused on purification and structural determination of the polar metabolites of TNT produced by strain MA01 are being undertaken and should distinguish between these possibilities.

In conclusion, the strategy of searching for an organism with proven aerobic deaminase and ring scission ability succeeded in isolating a bacterial strain capable of aerobic metabolism of the ADNT products of TNT nitro-group reduction. We are now using this organism in soil bioremediation experiments in which accumulation of these TNT reduction products proved problematic.

\section{Acknowledgments}

This work was performed under the auspices of the United States Department of Energy. We thank John L. Hanners for his help in the culturing of organisms and Elloise A. Margiotta for extensive literature searches.

\section{References}

Alvarez, M.A. 1993. Isolation and characterization of a 2,4,6trinitrotoluene degrading microorganism. M.S. thesis, Biology Department, New Mexico State University, Las Cruces, N.Mex.

Bochner, B.R., and Savageau, M.A. 1977. Generalized indicator plate for genetic metabolic and taxonomic studies with microorganisms. Appl. Environ. Microbiol. 33: 434.

Boopathy, R., Manning, J., Montemagno, C., and Kulpa, C. 1994. Metabolism of 2,4,6-trinitrotoluene by a pseudomonas consortium under aerobic conditions. Curr. Microbiol. 28: 131-137.

Bryant, C., and DeLuca, M. 1991. Purification and characterization of an oxygen-insensitive $\mathrm{NAD}(\mathrm{P}) \mathrm{H}$ nitroreductase from Enterobacter cloacae. J. Biol. Chem. 266: 4119-4125.

Carpenter, D.F., McCormick, N.G., Cornell, J.H., and Kaplan, A.M. 1978. Microbial transformation of ${ }^{14} \mathrm{C}$-labeled 2,4,6-trinitrotoluene in an activated-sludge system. Appl. Environ. Microbiol. 35: 949954.

Cartwright, N.J., and Cain, R.B. 1959. Bacterial degradation of the nitrobenzoic acids. 2. Reduction of the nitro group. Biochem. J. 73: 305-314.

Duque, E., Haidour, A., Godoy, F., and Ramos, J.L. 1993. Construction of a Pseudomonas hybrid strain that mineralizes 2,4,6-trinitrotoluene. J. Bacteriol. 175: 2278-2283.

Einistö, P., Watanabe, M., Ishidate, M., and Nohmi, T. 1991. Mutagenicity of 30 chemicals in Salmonella typhimurium strains possessing different nitroreductase or $O$-acetyltransferse activities. Mutat. Res. 259: 95-102.

Fernando, T., Bumpus, J.A., and Aust, S.D. 1990. Biodegradation of TNT (2,4,6-trinitrotoluene) by Phanerochaete chrysosporium. Appl. Environ. Microbiol. 56: 1666-1671.

Funk, S.B., Roberts, D.J., Crawford, D.L., Crawford, R.L. 1993. Initial-phase optimization for bioremediation of munition compoundcontaminated soils. Appl. Environ. Microbiol. 59: 2171-2177.

Gerhardt, P. (Editor). 1981. Manual of methods for general bacteriology. American Society for Microbiology, Washington, D.C.

Glaus, M.A., Heijman, C.G., Schwartzenbach, R.P., and Zeyer, J. 1992. Reduction of nitroaromatic compounds mediated by Streptomyces sp. exudates. Appl. Environ. Microbiol. 58: 1945-1951.

Hallas, L.E., and Alexander, M. 1983. Microbial transformation of nitroaromatic compounds in sewage effluent. Appl. Environ. Microbiol. 45: 1234-1241.

Hartter, D.R. 1985. The use and importance of nitroaromatic chemicals in the chemical industry. In Toxicity of nitroaromatic compounds. Edited by D.E. Rickert. Chemical Industry Institute of Toxicology Series, Hemisphere Publishing, New York. pp. 1-13.

Hathaway, J.A., 1985. Subclinical effects of trinitrotoluene: a review of epidemiology studies. Toxicity of nitroaromatic compounds. Edited by D.E. Rickert. Chemical Industry Institute of Toxicology Series, Hemisphere Publishing, New York. pp. 262-269.

Kaplan, D.L., and Kaplan, A.M. 1982. 2,4,6-Trinitrotoluene-surfactant complexes: decomposition, mutagenicity, and soil leaching studies. Environ. Sci. Technol. 16: 566-573.

Kitts, C.L., Cunningham, D.P., Unkefer, P.J. 1994. Isolation of three hexahydro-1,3,5-trinitro-1,3,5-triazine degrading species of the family Enterobateriacaea from nitramine explosives-contaminated soil. Appl. Environ. Microbiol. 60: 4608-4611.

Klausmeier, R.E., Appleton, J.A., DuPre, E.S., and Tenbarge, K. 1976. The enzymology of trinitrotoluene reduction. In Proceedings of the 3rd International Biodegradation Symposium, Naval Weapons 
Support Centre, Crane, Ind., 1976. Edited by J.M. Sharpley and A.M. Kaplan. Biodeterioration Society and Applied Science Publishers, London, U.K. pp. 799-805.

Loidl, M., Hinteregger, C., Ditzelmuller, G., Ferschl, A., and Steichsbeir, F. 1990. Degradation of analine and monochlorinated anilines by soil-borne Pseudomonas acidovorans strains. Arch. Microbiol. 155: 56-61.

McCormick, N.G., Herry, F.E., and Levinson, H.S. 1976. Microbial transformation of 2,4,6-trinitrotoluene and other nitroaromatic compounds. Appl. Environ. Microbiol. 31: 949-957.

Naumova, R.P., Selivanovskaya, Y., and Cherepneva, I.E. 1986. Conversion of 2,4,6-trinitrotoluene under conditions of oxygen and nitrate respiration of Pseudomonas fluorescens. Prikl. Biokhim. Mikrobiol. 24: 493-498.

Palleroni, N.J. 1984. Family 1. Pseudomonadaceae. In Bergey's manual of systematic bacteriology. Vol. 1.Edited by N.R. Krieg and J.G. Holt. The Williams \& Wilkins Co., Baltimore, Md. pp. 141219.

Robertson, J.B., Spain, J.C., Haddock, J.D., and Gibson, D.T. 1992. Oxidation of nitrotoluenes by toluene dioxygenase: evidence for a monooxygenase reaction. Appl. Environ. Microbiol. 58: $2643-$ 2648.

Schackmann, A., and Müller, R. 1991. Reduction of nitroaromatic compounds by different Pseudomonas species under aerobic conditions. Appl. Microbiol. Biotechnol. 34: 809-813.
Spain, J.C., Wyss, O., Gibson, D.T. 1979. Enzymatic oxidation of p-nitrophenol. Biochem. Biophys. Res. Commun. 88: 634-641.

Spanggord, R.J., Spain, J.C., Nishino, S.F., and Mortelmans, K.E. 1991. Biodegradation of 2,4-dinitrotoluene by Pseudomonas sp. Appl. Environ. Microbiol. 57: 3200-3205.

Valli, K., Brock, B.J., Joshi, D.K., and Gold, M.H. 1992. Degradation of 2,4-dinitrotoluene by the lignin-degrading fungus Phanerochaete chrysosporium. Appl. Environ. Microbiol. 58: 221 -228.

Vanderberg, L.A., Perry, J.J., and Unkefer, P.J. 1995. Catabolism of 2,4,6-trinitrotoluene by Mycobacterium vaccae. Appl. Microbiol. Biotechnol. 42. In press.

Vorbeck, C., Lenke, H., Fischer, P., and Knackmuss, H. 1994. Identification of a hydride-Meisenheimer complex as a metabolite of 2,4,6-trinitrotoluene by a Mycobacterium strain. Appl. Environ. Microbiol. 176: 932-934.

Williams, R.T., and Ziegenfuss, P.S., and Marks, P.J. 1988. Field demonstration composting of explosives-contaminated sediments at the Lousiana Army Ammunition Plant (LAAP). Final report. U.S. Army Toxic and Hazardous Materials Agency. Contract No. DAAK-11-85-D-007. U.S. Army Report No. AMXTH-IR-TE-88242.

Zeyer, J., and Kocher, H.P. 1988. Purification and characterization of a bacterial nitrophenol oxygenase which converts $o$-nitrophenol to catechol and nitrite. J. Bacteriol. 170: 1789-1794. 